\title{
Atrioventricular Septal Defect Associated with Noncompacted Myocardium
}

\begin{abstract}
The presented case conveys two significant clinical messages. Firstly, the embolic risk for patients with non-compacted myocardium is high and anticoagulants should be prescribed in case of left ventricular dysfunction or atrial fibrillation even if the CHA2DS2-VASc score is low. Secondly, the presence of ventricular arrhythmias in a patient with congenital heart disease and preserved biventricular function should lead to search for other causes of enhanced arrhythmic substrate, such as non-compacted myocardium.
\end{abstract}

Keywords: Non-compacted myocardium; Ventricular arrhythmias

\begin{tabular}{|c|}
\hline Case Report \\
\hline Volume 2 Issue 6 - 2015 \\
\hline $\begin{array}{l}\text { Silvia Iancovici }{ }^{1 *}, \text { George Giannakoulas }^{2} \text {, } \\
\text { Stelios Paraskevaidis }{ }^{2} \text {, George } \text { Spanos }^{3} \text { and } \\
\text { Haralambos Karvounis }{ }^{2}\end{array}$ \\
\hline $\begin{array}{l}{ }^{1} \text { Cardiology Department, Clinic Emergency Hospital of } \\
\text { Bucharest, Romania } \\
{ }^{2} \text { Cardiology Department, AHEPA University Hospital, Greece } \\
\text { 3Radiology Department, Greece }\end{array}$ \\
\hline $\begin{array}{l}\text { *Corresponding author: Silvia Iancovici, Cardiology } \\
\text { Department, Clinic Emergency Hospital of Bucharest, Calea } \\
\text { Floreasca No. 8, Sector 1, } 014461 \text { Bucharest, Romania, Tel: } \\
\text { 004021 5992300; Fax: 0040215992257; Email: } \\
\text { silvia stavarache@yahoo.com }\end{array}$ \\
\hline Received: February 25, 2015 | Published: June 01, 2015 \\
\hline
\end{tabular}

left ventricle, but biventricular involvement has frequently been reported. Noncompaction of the left ventricle has been described as an isolated cardiomyopathy but may also be encountered in association with other abnormalities, such as congenital heart disease and neuromuscular disease [2]. Left or right ventricular outflow tract obstruction, atrioventricular valve abnormalities and conotruncal lesions are the most common congenital heart lesions that are associated with non-compacted myocardium [3]. The main clinical manifestations of non-compacted myocardium are arrhythmias, heart failure due to left ventricular systolic dysfunction and embolism [3,4]. Management of these patients should be tailored based on these complications.

\section{Conclusion}

The association between congenital heart disease and noncompacted myocardium has already been described, but there is currently no prognostic significance of this clinical entity.

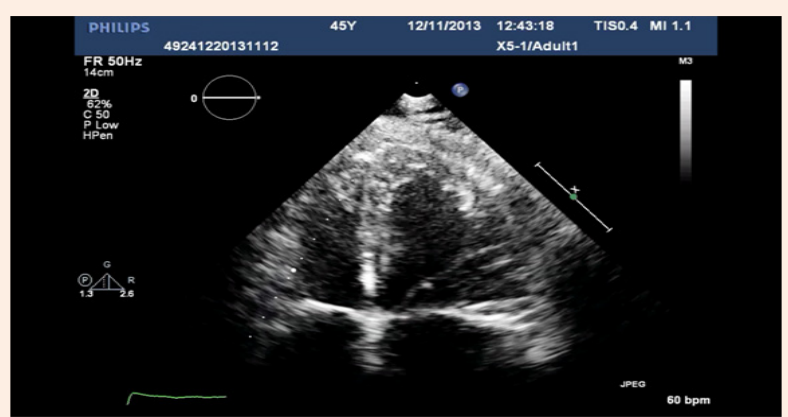

Figure 1A: Four-chamber echocardiographic view showing increased wall thickness in the left ventricular apical segments .

A 24-hour Holter monitoring performed 3 months before admission documented episodes of non-sustained ventricular tachycardia and, therefore, she underwent an electrophysiological study before the implantation of a cardioverter-defibrillator (ICD). A ventricular tachycardia followed by ventricular fibrillation was induced and an ICD was implanted. Two years after ICD implantation the patient experienced an episode of sustained ventricular tachycardia converted with antitachycardia pacing (Figure 3). Noncompaction of the left ventricular myocardium is a rare condition thought to be determined by intrauterine arrest of compaction of the loose interwoven meshwork that gives rise to the fetal myocardial fibers [1]. The disease uniformly affects the 


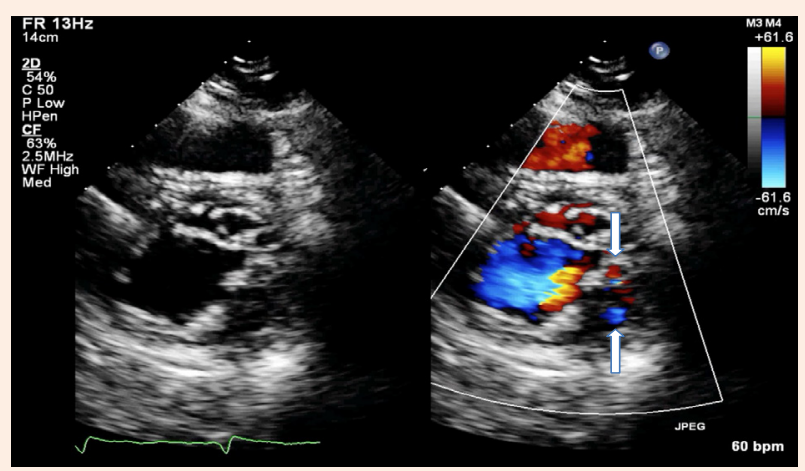

Figure 1B: Parasternal short-axis echocardiographic view showing the typical prominent trabeculations and intertrabecular recesses (left) and how the color enters the intertrabecular recesses (right, white arrows).

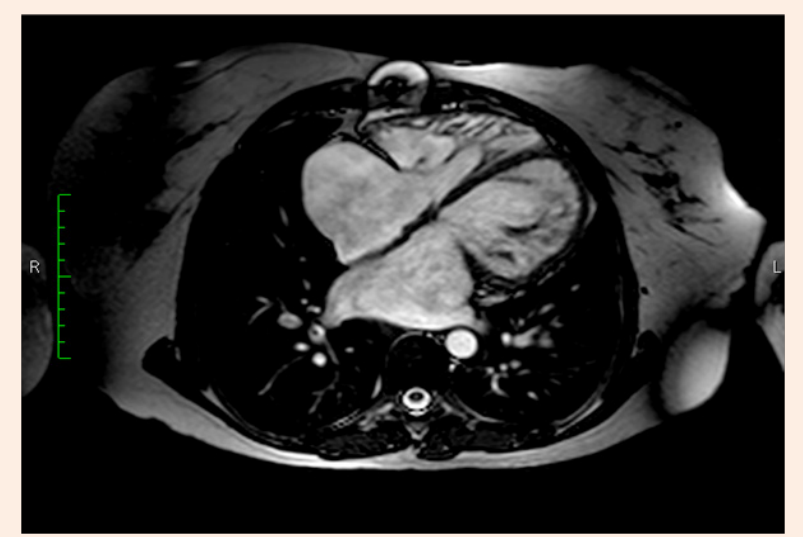

Figure 2: Four-chamber steady-state free precession (SSFP) cine image showing biventricular noncompaction at mid and apical levels.

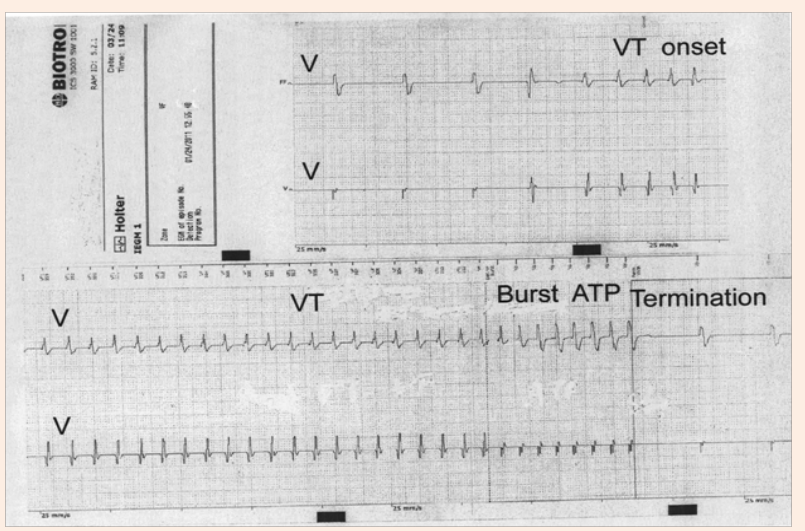

Figure 3: ICD recording showing the episode of ventricular tachycardia. Both channels record ventricular (V) electrograms. ATP: Antitachycardia pacing.

\section{References}

1. Jenni R, Oechslin E, Schneider J, Attenhofer Jost C, Kaufmann PA (2001) Echocardiographic and pathoanatomical characteristics of isolated left ventricular non-compaction: a step towards classification as a distinct cardiomyopathy. Heart 86(6): 666-671.

2. Weiford BC, Subbarao VD, Mulhern KM (2004) Noncompaction of the ventricular myocardium. Circulation 109(24): 2965-2971.

3. Stähli BE, Gebhard C, Biaggi P, Klaassen S, Valsangiacomo Buechel E, et al. (2013) Left ventricular non-compaction: prevalence in congenital heart disease. Int J Cardiol 167(6): 2477-2481.

4. Ichida F (2009) Left ventricular noncompaction. Circ J 73(1): 19-26. 